FACULTEIT ECONOMISCHE EN TOEGEPASTE ECONOMISCHE WETENSCHAPPEN DEPARTEMENT TOEGEPASTE ECONOMISCHE WETENSCHAPPEN

NAAMSESTRAAT 69 B-3000 LEUVEN

KATHOLIEKE UNIVERSITEIT LEUVEN

\title{
Are Prosocials Unique in Their Egalitarianism? The Pursuit of Equality in Outcomes Among Individualists.
}

Bram Van den Bergh and Siegfried Dewitte

University of Leuven

David De Cremer

Tilburg University

Submission date: August, 2005

Journal: Personality and Social Psychology Bulletin

Word count: 9186

BRAM VAN DEN BERGH 


\begin{abstract}
The present research aims to elucidate to what extent the motive to ensure equality in outcomes is general and to what extent it interacts with other important motives such as maximizing own or collective gains. Because individuals may have different considerations and motivations in decision-making situations, it is likely that people with a different social value orientation will respond differently to an unequal distribution of outcomes. Contrary to our expectations, not only prosocials care about equality in outcomes. In study 1 , we found that individualists choose to forego personal gains, despite obvious selfish reasons to cooperate, when outcomes were distributed unequally. In a second experiment we replicate this finding and show that individualists, just as do prosocials, demand equality in outcomes in interdependent situations. Our studies suggest that typifying individualists as solely being concerned about enhancing personal outcomes is too limited.
\end{abstract}

KEYWORDS: Equality, Social Values, Tit-For-Tat, Cooperation 


\section{Are Prosocials Unique in Their Egalitarianism?}

\section{The Pursuit of Equality in Outcomes Among Individualists.}

How to divide a pie? Providing yourself with the biggest slice might be a convenient partition if you made the pie yourself. Dividing it in equal parts may be appropriate if each party is equally deserving. An interesting option is to make a bigger pie. In two behavioral experiments we offer individuals the latter possibility: Participants can work together to increase the total size of the pie and hence increase the size of their own slice. While people may be eager to make a bigger pie if slices are distributed equally, the willingness to make a bigger pie may quickly dissipate if slices vary in size. Our aim in the present research is to elucidate to what extent the motive to ensure equality in outcomes is general and to what extent it interacts with other important motives such as maximizing own or collective gains.

By making use of the Prisoner's Dilemma Game (PDG) we will evaluate to what extent people are willing to increase cooperation (make a bigger pie) when the outcomes are distributed unequally. Because individuals may have different considerations in decision-making situations (e.g. maximizing the size of the personal slice versus an equal distribution of the pie), it is likely that people with a different social value orientation will respond to an unequal distribution of outcomes in different ways. More precisely, we distinguish between people with the motive to enhance equality in outcomes (i.e. prosocials) and people with the motive to maximize the size of their own pie (i.e. individualists). We argue that people differing in these motives will interpret inequalities in different ways and therefore will react differently to the opportunity to increase the pie when it is distributed unequally. To examine this, we introduce a new strategy in the PDG, known as Tit-For-Tat-Minus-1 (TFT-1), which is a strategy that is compatible with the motive to maximize the size of your own personal pie, while at the same time being irreconcilable with the motive to minimize the differences between the actors.

\section{Computer strategies and human cooperativeness}

A social dilemma is a situation in which interdependent actors confront a conflict between maximizing personal or collective outcomes. No matter how fellow actors react to this mixed-motive situation, it is in the actor's personal interest to behave selfishly. However, if all actors choose not to cooperate, all persons are worse off than if everyone had acted for the collective welfare (Dawes, 1980). Researchers have been interested in the determinants of cooperation in various types of social dilemmas, but the most frequently studied mixed-motive situation is probably the Prisoner's Dilemma Game (PDG). Among the vast amount of research 
on cooperation in interdependent situations, a number of studies have focused on the effects of the opponent's strategy on the actor's cooperative and competitive choices in repeated PDGs (e.g. Kuhlman \& Marshello, 1975; McClintock \& Liebrand, 1988; Parks \& Rumble, 2001; Van Lange \& Visser, 1999). Typically, pairs of players are led to believe that they are playing against each other, but in reality, they are playing against preprogrammed strategies. These studies have principally focused on three distinct strategies: $100 \%$ cooperation $(=$ an unconditionally cooperative strategy), $100 \%$ defection (= an unconditionally noncooperative strategy) and Tit-forTat (TFT).

TFT is a reciprocal strategy that begins with a cooperative choice and subsequently imitates the opponent's previous choice. Axelrod (1984) conducted computer tournaments using iterated two-person Prisoner's Dilemma Games, with the players being preprogrammed strategies submitted by experts on game theory. The strategy that yielded the largest mean total payoff in the tournaments was TFT. Studies comparing various types of strategies indicate that TFT is indeed very effective in eliciting cooperation in human actors and thus in increasing the joint outcome (e.g. Oskamp, 1971; Kuhlman \& Marshello, 1975; McClintock \& Liebrand, 1988; Van Lange \& Visser, 1999; Wilson, 1971). TFT's effectiveness seems to rely on a set of properties that characterize this strategy (Axelrod, 1984). First, TFT is considered to be a nice strategy, because it never initiates noncooperation. Second, TFT is retaliatory because it instantly matches the partner's noncooperative behavior. Third, when the opponent returns to cooperation, TFT also does and immediately forgives any defection in the past. Fourth, TFT is clear because the other learns the contingency between his/her actions and the subsequent matching by TFT. One of TFT's most important strengths is that it cannot be consistently exploited. Whenever the actor defects and TFT cooperates, the TFT strategy will get the least attractive option (= the sucker's payoff). On the subsequent round, TFT matches the actor's choice and defects in response to the actor's defection. Therefore, continuous exploitation of TFT is impossible and competition with TFT is futile. Typically, a TFT strategy yields greater cooperation with a human actor than an unconditionally cooperative strategy, which in turn elicits greater cooperation than an unconditionally noncooperative strategy.

\section{The importance of equality}

Interestingly, despite its effectiveness, even TFT does not succeed in eliciting cooperation among human subjects in situations in which payoffs are distributed unequally. For example, Parks, Rumble and Posey (2002) showed that people attend to and react to the difference between own and others' outcomes: Individuals receiving outcomes of a smaller magnitude become uncooperative and those who receive large outcomes become very cooperative. The negative 
reaction to the unequal distribution of outcomes is detrimental for cooperation and the effectiveness of TFT in inducing cooperativeness seems limited in these situations. People can be concerned about interpersonal comparisons to such an extent that they prefer outcomes that reduce their own and other parties' payoffs in an effort to avoid inequalities. Indeed, it has been found that subject rate a payoff of $\$ 500$ for self / $\$ 500$ for other as more satisfying than $\$ 600$ for self / \$800 for other; the extra \$100 in the second outcome may not be worth the \$200 inequality (Loewenstein, Thompson, \& Bazerman, 1989). Also in ultimatum games similar effects have been found. In those situations, one player proposes a distribution of a fixed amount of money and the other has the option of either accepting or rejecting. Players frequently reject a positive but inequitable offer even though the alternative is no gain at all (Camerer \& Thaler, 1995; Guth, Schmittberger, \& Schwarze, 1982). However, in the present research we start from the assumption that the extent to which people value equality varies from one individual to the next (cf. Van Lange, 1999). Therefore, we will introduce a strategy that provokes equality considerations in a PDG to investigate whether the concern for equality is universal or individually different.

Because the standard PDG offers the participants only two options (cooperation vs. defection), more subtle strategies than $100 \%$ defection or $100 \%$ cooperation are not easily implemented. In reality, people can often decide about the extent of their cooperation, with complete defection, or complete cooperation being only two extremes in a range of options. In the present research, we implement a strategy that has not been examined yet, that is, a Tit-for-Tatminus-1 (TFT-1) strategy. This strategy is equivalent to the classic TFT strategy, but undercuts the cooperative choice of the actor by a small amount. This contingent competitive strategy starts with a nice cooperative move (like TFT) and mimics the actor's choices on subsequent trials, after diminishing the actor's contribution with a small, constant amount. Like TFT, TFT-1 is retaliatory (TFT-1 decreases cooperation after defection), forgiving (TFT-1 raises cooperation if the actor does so) and easy to understand (the actor learns the contingency between his choices and TFT-1 matching).

Previous research has already implemented modifications of TFT: TFT +1 is a more generous version of TFT and is slightly more cooperative than the actor on subsequent rounds (Van Lange, Ouwerkerk, \& Tazelaar, 2002). Tit-For-Two-Tats defects only after two consecutive defections and is thus a more forgiving variant on TFT. Suspicious-Tit-For-Tat acts like TFT but defects on the first round. Our own modification of TFT provokes equality considerations, because TFT-1 gets a higher payoff on each round. Our aim in implementing this contingent competitive strategy is triggering concerns about equality. 'Rational' players find a good partner in TFT-1 because this strategy is compatible with the motive to maximize own outcomes. As long 
as individuals are avoiding comparison of outcomes against TFT-1, they would be willing to increase cooperation with this strategy, since a rise in one's own cooperation is followed by an increase in TFT-1's cooperativeness. Cooperating with TFT-1 is analogous to making a bigger pie of which the slices vary in relative size. Research indicates that individuals differ with respect to the type of goal they are motivated to maximize in a PDG (e.g. Kuhlman \& Marshello, 1975). TFT1 seems a suitable strategy to explore whether the motive to enhance personal gains dominates the tendency to enhance equal outcomes or vice versa. Some people are solely concerned about maximizing own payoffs, whereas other individuals take into account the equal distribution of resources. Since individuals with different motives can respond to the same strategy in different ways, we will make diverging predictions regarding cooperativeness with TFT-1. The social utility model (e.g. Loewenstein, Thompson, \& Bazerman, 1989) suggests that both inter- and intrapersonal comparisons are important in social decision-making. Two utility sources may determine choices in distributive decision-making: The first source reflects the concern about own outcomes (intrapersonal comparison: compare own outcomes in one situation with own outcomes in another situation). The second source reflects the weight assigned to own outcomes in relation to others' outcomes (interpersonal comparison: comparison between one's own outcomes and those of others). We will assume that the first source is of great importance to all people, while the second may only be of concern to one class of individuals.

Equality in outcomes: Only considered by prosocials?

Axelrod (1984) showed that TFT consistently ended up victoriously over many interactions with many different partners. Yet, TFT never outcompeted its partner in any single interaction: TFT either ties or earns less than its opponent. This led Axelrod to suggest that TFT's long-term success relies on its lack of envy of the partner's payoffs. Previous literature suggests that the concern for equality and the resulting envy is subject to individual differences. Some people pay little or no regard to outcomes for others (e.g. Messick \& McClintock, 1968) and are solely concerned about their own payoffs. Still, the equality rule may serve as a useful heuristic in decision-making situations (Messick, 1993; Samuelson \& Allison, 1994) even for people who strive to maximize their own payoff (Stouten, De Cremer, \& van Dijk, in press). In this research we attempt to explore the strength of the motive to minimize the differences between the actors and to what extent it dominates other motives as maximizing own gains.

Different individuals assign different weights to their own and to others' outcomes and as a consequence, people systematically differ in the tendency to prefer particular distributions of outcomes for self and others in interdependent situations (McClintock, 1972). People sometimes forego their own selfish interests and act for the benefit of the collective (e.g. Dawes \& Thaler, 
1988; Kuhlman \& Marshello, 1975; Messick \& McClintock, 1968). An individual's social value orientation can be defined as a relatively stable preference for specific distributions of outcomes for oneself and others (e.g. Messick \& McClintock, 1968; Van Lange, 1999). Although theoretically one could distinguish a variety of social value orientations, in the literature, a three-category typology has been typically identified and seems to cover the most common orientations: An individualistic orientation (i.e. maximization of one's own outcomes with little or no regard for outcomes for others, MaxOwn), a competitive orientation (i.e. maximization of relative advantage over others, MaxRel) and a prosocial orientation (i.e. maximization of outcomes for both self and others, MaxJoint, and minimization of differences between outcomes for self and others, MinDiff).

One established conceptualization of social value orientation identifies the motive to maximize joint outcomes as central to the prosocial orientation (e.g. Messick \& McClintock, 1968). However, as noted by Van Lange (1999), De Cremer and Van Lange (2001) and Eek and Gärling (in press), a MaxJoint transformation of a given matrix cannot account for all actions of prosocials. For example, the MaxJoint motive in itself cannot explain why prosocial individuals turn to noncooperative behavior in interaction with noncooperative people (e.g. Kelley \& Stahelski, 1970). The integrated model of social value orientation (Van Lange, 1999) states that the prosocial orientation is to be understood in terms of both the tendency to enhance joint outcomes (MaxJoint) and the tendency to minimize the differences between own and others' outcomes (MinDiff). In Van Lange's integrative model (1999) it is assumed that the desire for equality in outcomes is virtually absent in individualists and competitors, since only prosocials put substantive weights on equality. The MinDiff motive is crucial to understand differences between prosocials and individualists, but has been fairly overlooked in social value orientation research (but see, van Dijk, De Cremer, \& Handgraaf, 2004). In this research we want to investigate whether the motive to enhance equality is indeed unique to prosocials. Although the equality rule could be applied by both proselfs (individualists and competitors) and prosocials, research suggests that prosocials prefer the equality rule out of fairness concerns, whereas for proselfs efficiency concerns dominate (Stouten, De Cremer, \& van Dijk, in press). In decisions on how to distribute a certain amount of money, prosocials may propose an equal split out of a true concern about a fair distribution of outcomes, whereas proselfs in contrast propose an equal split mainly out of strategic considerations (van Dijk, De Cremer, \& Handgraaf, 2004). Because of these different considerations in decision-making situations, people with a different value orientation can respond in a PDG to the same strategy in different ways (e.g. McClintock \& Liebrand, 1988; Van Lange \& Visser, 1999). The behavioral patterns of cooperation among individualists and 
prosocials in interaction with a TFT-1 strategy might shed additional light on the importance of MinDiff in prosocials and individualists.

\section{Prosocials}

Typically, prosocial people are willing to cooperate, as long as cooperation is reciprocated. Prosocials adapt their choices to a noncooperative individual (Kelley and Stahelski, 1970) and are likely to reciprocate noncooperative behavior (Komorita, Hilty, \& Parks, 1991). If cooperation is not reciprocated, prosocials lose patience and become noncooperative. Kelley and Stahelski coined this uncooperative behavior of prosocials "behavioral assimilation". According to Van Lange's (1999) integrative model prosocial behavior is to be understood both in terms of enhancing joint outcomes and equality in outcomes. Consistently, Parks and Rumble (2001) found that prosocials' willingness to be exploited for possible, greater gains is limited. Our procedure was designed to pit the two motives of prosocials against each other. Three scenarios could be conceived. First, if MaxJoint dominates any other motive, we expect an increase in cooperation with both TFT and TFT-1 because cooperation with both strategies maximizes the joint pay-off. Second, if MinDiff is the most crucial motive among prosocials, as hypothesized by Eek and Gärling (in press), decreasing levels of cooperation in interaction with TFT-1 should prevail. Against TFT, prosocials should maintain their initial cooperation level, since any rise in cooperation would be incompatible with MinDiff: The result of an increase in cooperation is a small sucker's payoff for the actor on the subsequent round. Increasing cooperation against a TFT strategy means receiving less than TFT on the subsequent round, because TFT will reciprocate the lower level of cooperation of the previous round. The increase in cooperation is only reciprocated by TFT on the next to subsequent round. Therefore, an increase in cooperation is compatible with the MaxJoint and MaxOwn motive, but implies an unequal distribution of payoffs in the TFT condition. Hence, if MinDiff dominates any other motive, we should expect prosocials to maintain their initial level of cooperation, without increasing their cooperation,. The third possibility is that the opponent strategy determines which motive will dominate. We hypothesize that, when interacting with TFT-1, prosocials' motive to minimize differences in outcomes would dominate the motive to maximize joint gains. However, when interacting with TFT, prosocials' motive to maximize joint outcomes would dominate the motive to minimize the differences between the two actors.

\section{Individualists}

Individualists enter an interaction focusing on how to maximize long-term selfish interests. Individualists are motivated to maximize own gains, irrespective of the outcomes for others. Therefore, individualists display low levels of cooperation against $100 \%$ cooperative, because they exploit this strategy and in this way maximize their own payoffs (e.g. Kuhlman \& 
Marshello, 1975). Individualists take advantage of cooperative partners, but cooperate if there are selfish reasons for cooperation. If the partner pursues a reciprocal strategy, such as TFT, exploitation is futile and individualists increase their levels of cooperation, since cooperation, and not exploitation, maximizes their long-term outcomes. Individualists learn that against TFT their gain is most effectively maximized by cooperation. Previous studies indicate that TFT is indeed effective in inducing cooperation among individualists (e.g. Kuhlman \& Marshello, 1975). The predictions for levels of cooperation in interaction with TFT-1 are quite straightforward. According to Van Lange's (1999) integrative model of social values, equality concerns as triggered by TFT-1 are virtually absent in individualists (or at least less pronounced). Like TFT, TFT-1 is unexploitable and hence, the maximization of personal outcomes is compatible with cooperation and not with exploitation. High levels of cooperation with TFT-1 enhance personal outcomes, as long as an individual is not concerned about how others are doing. Individualists, by definition, pay little or no regard for outcomes for others (e.g. Messick \& McClintock, 1968), and will not be concerned with the higher payoff of TFT-1. Hence, we predict that the strategy pursued by the opponent will have a small or negligible effect on individualists: Exploitation of TFT or TFT-1 is futile, and given their focus on maximizing own payoffs, they should display a willingness to cooperate with both strategies. We could also predict that individualists, compared to prosocials, are more eager to increase cooperation with TFT. This strategy serves their dominant MaxOwn well and they are not limited by concerns about an equal distribution of payoffs (MinDiff) to raise the stakes.

\section{Competitors}

TFT-1 might be less useful in investigating competitors' motives. Because competitors strive to maximize their relative advantage in comparison with the opponent (Van Lange 1999), even TFT is not successful at inducing cooperation in competitors. Kuhlman and Marshello (1975) reported that competitors did not accommodate to the nonexploitable TFT strategy: they continued to defect throughout a series of interactions. McClintock \& Liebrand (1988) reported that competitors were the least sensitive to variations in the strategies of others. Competitors defect regardless of the other's strategy (Kelley \& Stahelski, 1970). Therefore, it seems likely that TFT-1, if anything, will only further reduce cooperation in competitors. Nevertheless, it is likely that competitors' behavior will differ from individualists', which makes the common merger (e.g. De Cremer \& Van Lange, 2001) of competitors and individualists into one proself category problematic in this study. Because competitors are relatively rare and because we did not expect much additional insights from including them, we decided not to focus our attention to this category in the present studies. 
To summarize, pairs of players will be led to believe that they are playing against each other, but in reality, they will be playing against preprogrammed strategies. We will try to elucidate to what extent the motive to enhance equality in outcomes is general and to what extent it dominates motives such as maximizing own or joint outcomes. Individualists and prosocials will interact with TFT and TFT-1 in a repeated PDG and their increase or decrease in cooperativeness will allow us to deduce which motives are dominating their decision in the PDG.

\section{Study 1}

\section{Method}

Participants. Students $(\mathrm{N}=57)$ from a West-European University were recruited via the internet and participated in a repeated Prisoner's Dilemma Game (PDG) with variable investment (adopted from Van Lange, Ouwerkerk, \& Tazelaar, 2002). Research sessions were attended by five to eight participants. Participants were seated in partially enclosed cubicles, which prevented them from communicating with each other. They participated in return for a participation fee that varied with their payoff in the experimental PDG (between $€ 6$ and $€ 8$.5). Participants knew that the total number of coins gathered throughout the experiment was used to calculate the participation fee. This made sure that decisions made in the experiment were relevant and that concerns about equality would have an impact on their participation fee.

Assessment of Social Value Orientation. Social value orientation was assessed by a nine item decomposed game measure (Messick \& McClintock, 1968), adopted from prior research (see e.g. Van Lange et al., 1997). As an example we describe one decomposed game. The participant is offered a choice among three options: Option A, yielding 480 points for self and 80 points for other; option B, yielding 540 points for self and 280 points for other; and option C, yielding 480 points for self and 480 points for other. Option A maximizes the difference between one's own and the other's outcomes $(480-80=400)$. Therefore, option A represents the competitive choice, since option A yields a greater relative advantage than option B $(540-280=260)$ or option C (480$480=0$ ). Option B maximizes one's own outcomes (540) and represents the individualistic choice because personal gains are larger than those in option A (480) or option C (480). Option C represents the prosocial choice, because $(1)$ it provides a larger joint outcome $(480+480=960)$ than does either option A $(480+80=560)$ or option B $(540+280=820)$ and because (2) it represents a smaller discrepancy between one's own and other's outcomes $(480-480=0)$ than does either option A $(480-80=400)$ or option B $(540-280=260)$. Option C is therefore consistent with the motive to enhance joint outcome as well as equal outcomes. Nine such sets of 3 options are presented and the test is scored by tallying how many times each motive is selected. A value orientation is assigned if the respondent selects at least six times the same motive. Following these criteria, we 
identified $32(56 \%)$ participants as prosocial, $14(24 \%)$ as individualistic, and $2(3 \%)$ as competitive; 9 participants (15\%) could not be classified. As explained in our introduction, we only consider prosocials and individualists.

Procedure. The task was conducted on PC. The instructions for the repeated PDG were provided on PC (programmed in Macromedia Authorware). Participants were allocated $€ 10$ in each round of the repeated PDG, which they could either keep to themselves or donate to the other player in units of $€ 1$ (ranging from 0 to 10 coins). Each $€ 1$ kept was added to the participant's account. Each $€ 1$ donated was doubled by the experimenter and added to the partner's account. The possible outcomes of the game were presented in an 11 by 11 matrix that could be consulted throughout the experimental task. The participant and the partner made their choices simultaneously and participants were informed about the partner's decisions prior to making a new choice. After explaining the game, the participants became acquainted with the choice procedure by 5 iterations of the task. These 5 test iterations made it clear that choices were made simultaneously. Participants were informed that their PC would be connected with another PC on a random basis and that choices were made anonymously. Participants were unaware of the number of iterations of the game that would be played.

Strategy. Participants played, unbeknownst to them, against a preprogrammed computer strategy. TFT was programmed to begin by giving 6 coins out of 10 to the participant (see Van Lange, Ouwerkerk, \& Tazelaar, 2002). In subsequent rounds, TFT was programmed to give exactly the same number of coins that the participant had given in the previous interaction round. The 'Tit-For-Tat-Minus-1' (TFT-1) strategy started by giving 6 coins on the first round and was programmed to subtract 1 coin from the participant's previous choice in the subsequent round. As soon as all participants had finished the first interaction phase, they changed places and interacted in a second PDG. All participants interacted once with TFT and once with TFT-1 in a randomized order. Order did not have an effect and is ignored in the remainder.

Dependent Variable. In order to investigate whether the level of cooperation increased versus decreased throughout the interaction, a slope was computed for each participant. The X-axis represented 'round number' and 'amount of coins given away to the partner' is plotted on the $Y$ axis. Slopes are compared across the TFT and TFT-1 conditions. Positive slopes indicate that participants increase the level of cooperation throughout the interaction and negative slopes indicate a decrease in cooperation. One outlier was removed from the analyses.

Results

Insert Figure 1 about here 
A 2 (social value orientation) by 2 (strategy) within subjects analysis of variance, reveals a main effect for strategy, $F(1,90)=61.99, p<.0001$. The positive slopes $(M=0.18$; significantly different from zero, $t(44)=5.5, p<.0001)$ in the TFT condition indicate that cooperation increases in interaction with a strategy that matches the player's cooperation. Playing against a TFT-1 strategy yielded negative slopes ( $M=-0.38$; significantly different from zero, $t(44)=-5.64, p<.0001)$, which indicates that participants decreased their cooperativeness over the course of an interaction with a strategy that undercuts the player's cooperativeness. The analysis yielded a marginally significant main effect for social value orientation, $F(1,90)=3.41, p=0.07$. A planned comparison revealed a significant difference between prosocials and individualists in the TFT-1 condition, $F(1,90)=4.17, p<0.05$. Prosocials' slope $(\mathrm{M}=-0.27$; significantly different from zero, $t(30)=-4.40$, $p<.0001)$ dropped slower than individualists' $(\mathrm{M}=-0.48$; significantly different from zero, $t(13)=-$ $3.69, p<.01)$. A similar comparison yielded no significant difference between prosocials and individualists in the TFT condition, $F(1,90)=0.25$, NS. Prosocials $(M=0.20$; significantly different from zero, $t(30)=4.90, p<.0001)$ and individualists $(M=0.15$; significantly different from zero, $t(13)=2.49, p<.05)$ are statistically indistinguishable when they interact with a TFT strategy.

Discussion

It was predicted that the strategy pursued by the opponent would have a small or negligible effect on individualists. Since individualists are motivated to maximize own gains and do not care about equality in outcomes, we expected them to display high levels of cooperation with both TFT-1 and TFT. However, the findings of study 1 revealed that individualists, just as prosocials, did not attempt to increase cooperation with TFT-1, instead they decreased their level of cooperation throughout the interaction if equality was not established. Clearly, individualists' behavior in the TFT-1 condition cannot be explained by their motive to enhance personal outcomes. Enhancing the participation fee and personal outcomes is compatible with an increase in cooperation, not with a decrease. Other tendencies than MaxOwn seem to dominate the choice procedure among individualists in the TFT-1 condition. However, our results can be meaningfully interpreted if we assume that individualists do care about equality in outcomes, something that the integrative model of social value orientation does not predict. As such, individualists seem willing to forego a maximization of personal outcomes when there is no equality in outcomes. In fact, our findings even suggest that this aversion for inequality is more pronounced among individualists since they decrease cooperation significantly faster than prosocials. In the TFT condition however, our predictions were confirmed with respect to the individualists. That is, individualists increase cooperation throughout the interaction whenever the partner reciprocates the level of cooperation and thus, consistent with previous findings, TFT is found to be effective in eliciting cooperation among individualists. This finding adds to this 
literature because we replicate the success of TFT to elicit cooperation in individualists in a PDG with variable investment. Individualists are willing to pay a small sucker's pay-off to initiate a rise in cooperation. Results for prosocial individuals suggest that the dominant motive shifts according to the opponent's strategy. We observe a decrease in cooperation whenever the opponent undercuts the level of cooperation of the participant with a small amount, which implies that prosocials are not maximizing joint gains. In contrast, prosocials are willing to incur small and accumulating sucker's payoffs to enhance joint gains. This suggests that MaxJoint dominates over MinDiff in the TFT condition.

\section{Study 2}

Study 1 suggested that typifying individualists as being concerned only about enhancing personal outcomes falls short. Individualists do not maximize own gains when they interact with a strategy that undercuts their cooperativeness with a small amount, while cooperation with that strategy is compatible with their primary and basic tendency to enhance personal gains. Other motives than MaxOwn are to be invoked to explain individualists' behavior in the TFT-1 condition. Our major aim in the second study is to replicate this individualists' tendency to forego maximization of personal outcomes. Based on study 1 , we predict that individualists forego maximizing personal outcomes when outcomes are distributed unequally and that individualists would start to enhance personal gains only if outcomes are distributed equally. If we assume that the MinDiff motive causes individualists to decrease cooperation in interaction with TFT-1, we should expect an increase in cooperation as soon as this MinDiff motive dissipates. Therefore, we implement a shift in the partner's strategy after a given number of rounds. In our second experiment, all participants start interacting with TFT-1, but on round 21, the strategy shifts suddenly, unbeknownst to the participants, into a TFT strategy. We predict that individualists will continue decreasing cooperation as long as inequality in distribution of outcomes is enduring. After the shift in strategy, the MinDiff motive would vanish and individualists should start to maximize personal gains, regardless of the reputation that has been built up by their partner in the PDG. Regarding prosocial behavior we expect to replicate the findings of study 1: Decreasing cooperation in interaction with TFT-1 and increasing cooperation with TFT. In line with study 1 we explore whether this inequality aversion could be even more pronounced among individualists.

Method

Participants. Students ( $\mathrm{N}=82)$ from a West-European University were recruited via the internet and participated in a repeated Prisoner's Dilemma Game (PDG) with variable investment. We used the same recruiting procedure, participation fee and laboratory as in study 1 . 
Assessment of Social Value Orientation. The Triple Dominance Measure of Social Values (see e.g. Van Lange et al., 1997) was administered and we identified 42 (51\%) participants as prosocial, 19 $(23 \%)$ as individualistic, and $7(8 \%)$ as competitive; 14 participants $(17 \%)$ could not be classified. In further analyses we only consider prosocials and individualists.

Procedure. The procedure was identical to that of study 1. Participants were allocated $€ 10$ in each round of the repeated PDG, which they could either keep to themselves or donate to the other player in units of $€ 1$ (ranging from 0 to 10 coins).

Strategy. Participants played, unbeknownst to them, against a preprogrammed computer strategy. All participants interacted during 20 rounds with TFT-1. The TFT-1 strategy started by giving 6 coins on the first round and was programmed to subtract 1 coin from the participant's previous choice in the subsequent round. On round 21, the TFT-1 strategy turned into a TFT strategy and the interaction with TFT lasted for another 20 rounds. TFT started by reciprocating the number of coins given away on round 20 and was programmed to copy the actor's choices on subsequent rounds. No cues or indications of this shift in strategy was given to the participants: The interaction on round 21 continued as if nothing happened.

Dependent Variable. In order to investigate whether the level of cooperation increased versus decreased throughout the interaction, two slopes were computed for each participant. One slope was calculated for the interaction with TFT-1, another slope was calculated for the interaction with TFT. These slopes are compared between individualists and prosocials.

Results

Insert Figure 2 about here

The interaction with a TFT- 1 strategy during the first 20 rounds yields negative slopes $(M=-0.12$; significantly different from zero, $t(60)=-5.20, p<.0001)$ which indicates that participants decrease their cooperativeness over the course of an interaction with a strategy that undercuts the player's cooperativeness. The analysis yields no significant effect for social value orientation, $F(1,59)=1.37$, NS. With respect to the slopes, individualists and prosocials are statistically indistinguishable when they interact with a TFT-1 strategy. However, individualists playing against TFT-1 give significantly fewer coins in the rounds 15 to 20 than prosocials, $F(1,59)=4.22, p<.05$. Slopes differ significantly from zero, both for prosocials $(\mathrm{M}=-0.10), t(41)=-3.85, p<.001$, and individidualists $(\mathrm{M}=-0.16), t(18)=-3.52, p<.01$, indicating a decrease in cooperation throughout the interaction with TFT-1. With respect to the slopes calculated during the interaction with TFT from round 21 to round 40 , the analysis yields a significant effect for social value orientation, $F(1,59)=4.10, p<.05$. Individualists ( $M=0.22$ significantly different from zero, $t(18)=4.70, p<.001)$ increase their level of 
cooperation at a faster rate than prosocials $(\mathrm{M}=0.12$; significantly different from zero, $t(41)=4.61$, $p<.0001)$ when they interact with a strategy that matches their level of cooperation.

Discussion

Individualists' behavior in interaction with TFT-1 is an anomaly: Their choices can not be explained by MaxOwn. Instead of enhancing personal outcomes by cooperating with TFT-1, we replicate the finding that individualists decrease cooperation in interaction with TFT-1. Our second study is indicative for the presence of the MinDiff motive among individualists. Individualists' cooperation remains low as long as the unequal distribution of payoffs is enduring. Only when the strategy shifts to a more equality based orientation, the individualists' tendency to enhance personal outcomes is gaining ground. The MinDiff motive dissipates by the strategy switch from TFT-1 to TFT. The MaxOwn motive is clearly dominating the choice procedure after the switch and our findings suggest that the willingness to restore cooperation is even greater among individualists than among prosocials. One possibility is that the eagerness to increase cooperation is enhanced when one finds oneself in a bad situation and the motive to maximize own payoffs has become very salient, but this tentative explanation awaits further research.

\section{General Discussion}

In spite of Axelrod's prescription that players should not envy other's outcomes, making more pie, but getting smaller slices than one's partner, does not appear to be an attractive option. TFT-1 was designed such that cooperation was the optimal way to maximize personal gains. By giving all your coins $(=10)$ to TFT-1, you will receive $18\left(=2^{*}(10-1)\right)$ coins on the subsequent round. Through cooperation you almost double your starting capital and maximize your participation fee in the experiment. Obviously, TFT-1 will outperform you, since it receives 20 coins $(=2 * 10)$ and keeps 1 coin (TFT-1 gave you 9 coins and kept 1$)$, the net result for TFT-1 is thus 21 coins. Rational economic individuals find an excellent partner in TFT-1, as long as a comparison of one's own outcome with the partner's outcome is avoided. It is obvious that cooperation with TFT-1 is the optimal strategy to maximize both own and joint outcomes. Our results indicate that participants do not enhance personal or joint outcomes, irrespective of their social value orientation. Other motives than MaxOwn and MaxJoint are clearly dominating their choices in the TFT-1 condition in the PDG. If the partner pursues a TFT-1 strategy, exploitation is futile and participants should learn that cooperation, and not exploitation, maximizes their longterm outcomes (cf. Sheldon, 1999). While TFT-1 is retaliatory, forgiving, clear and starts with a nice and cooperative move, this competitive strategy is not capable of eliciting cooperation among individualists or prosocials. All these characteristics have been put forward as important 
features that contribute to the effectiveness of TFT in inducing cooperation (e.g. Axelrod, 1984). TFT-1 differs from TFT only on the equality dimension, because TFT-1 gets a higher payoff on each round. It seems that starting with a nice cooperative move, being retaliatory, forgiving and clear is not sufficient to elicit cooperation. Despite the prosocials' and individualists' similar reaction to TFT-1, each may have different perceptions of TFT-1. Whereas prosocials might have moral reasons to value equality in outcomes and may perceive their partner as dishonest or bad eventually leading to noncooperation, individualists may perceive TFT-1 as a too powerful partner to interact with on a cooperative basis. These perceptual differences have been referred to as the might versus morality effect (Liebrand et al., 1986; Van Lange \& Kuhlman, 1994) and indicate that similar reactions do not imply that prosocials and individualists perceive their partner in the same way or have the same reasons to turn to noncooperation. We feel it would prove insightful to complement data on cooperation with TFT-1 with data on the participants' perception of their partner. Unfortunately, our studies lack information on perceptions of TFT-1 and future research could present supplemental data on participants' perceptions of TFT-1, to uncover possible differences between prosocials and individualists in perceptions of TFT-1.

Previous research (e.g. De Cremer \& Van Lange, 2001; Van Lange, 1999) suggested that the prosocial orientation is to be understood in terms of enhancing both joint outcomes and equality in outcomes. In our experiments we have pitted the two prosocial motives (MaxJoint and MinDiff) against each other: Cooperation with TFT-1 is compatible with MaxJoint but incompatible with MinDiff. Based on the prosocial's noncooperativeness with TFT-1 we conclude that prosocial behavior is to be understood in terms of enhancing equality outcomes and that the motive to enhance joint gains is clearly of subordinate importance, since prosocials do not maximize joint outcomes in interaction with TFT-1. Recent experimental evidence points out that prosocials prefer equal outcomes to maximizing joint outcomes (Eek \& Gärling, in press), which is consistent with our finding that prosocials decrease cooperativeness in interaction with TFT-1. Additionally, previous research suggested already that the willingness among prosocials to be exploited for eventual greater gain is limited (Parks \& Rumble, 2001). However, the presentation of information in alternative forms plays a critical role in determining the degree to which individuals weigh interpersonal comparisons (Bazerman, Loewenstein, \& White, 1992). Experimental research indicates that subjects rate the outcome of $\$ 500$ for self / $\$ 500$ for other as more desirable than the outcome $\$ 600$ for self / $\$ 800$ for other when both are evaluated independently, but subjects choose the latter outcome over the former when presented with the two options simultaneously (Bazerman, Loewenstein, \& White, 1992). Prosocials may thus only care about maximizing joint gains when the option which minimizes differences between outcomes and the option which maximizes joint gains are offered simultaneously. This may serve 
as an hypothetical explanation for prosocials' decreasing cooperativeness with TFT-1. In contrast, prosocials are willing to be exploited for greater joint gains when they interact with TFT. An increase in cooperation results in a small sucker's payoff on the subsequent round. In contradiction with Eek \& Gärling (in press), prosocials increase cooperation against TFT (and maximize joint outcomes). Through cooperation with TFT, prosocials incurr small, but accumulating, exploitation costs that are incompatible with their MinDiff motive. Thus, we find that under TFT conditions, the prosocial motive to maximize joint gains is of greater importance than the tendency to enhance equal outcomes. Our findings indicate that different motives guide prosocial choices and that one motive could be of greater importance than the other, depending on who they are dealing with.

By far the most intriguing finding of our two experiments is that individualists decrease cooperation against TFT-1. Although there are obvious selfish reasons to cooperate (which is an often cited explanation for cooperation among individualists), TFT-1 does not succeed in initiating cooperativeness among individualists. Cooperation with TFT-1 is the optimal way to maximize personal outcomes (and thus, to maximize the participant's participation fee), but in our two studies individualists forego personal gains and decrease their cooperativeness. Research indicates that individualists move toward cooperation when consistent exploitation is impossible (Parks \& Rumble, 2001) and this makes our findings even more surprising: TFT-1 is not exploitable and individualists should learn that cooperation, and not exploitation, is in their own selfish interest. We assumed that intrapersonal comparisons were of greater importance than interpersonal comparisons to individualists. We hypothesized that individualists compare their own situation before they make a choice with their situation after their choice. Clearly, this is not correct. Typifying individualists as being concerned only about enhancing personal outcomes, with little or no regard for outcomes for others, appears to fall short. The data suggest that in the pursuit of outcomes, individualists also engage in social comparison: This might imply that the integrative model of social values has to be adapted or that decomposed measures to typify people as prosocials, individualists or competitors are flawed. Individualists' decreasing cooperation against TFT-1 strongly suggests that other motives than MaxOwn may affect individualists' behavior.

Our results are consistent with the finding that interpersonal comparisons can overwhelm or overshadow concern for personal outcomes (Bazerman, White, \& Loewenstein, 1995; Loewenstein, Thompson, \& Bazerman, 1989), even for those individuals most concerned with personal gains. Stouten, De Cremer, and van Dijk (in press) also found that proselfs display emotional reactions towards violations of equality, which is consistent with our contention. However, these emotions were function of the success or failure of their cooperative choices: 
When a public good was eventually obtained despite violations of equality, proselfs reacted less negative to these violations; whereas prosocials reacted to violations of equality regardless of whether the public good was obtained or not. Our findings add to this, since individualists could obtain success easily by cooperating. Cooperation augments their starting capital during their interaction with TFT-1, which yields an intrapersonal comparison that results in a positive 'emotion'. Yet they are more concerned about minimizing the differences between the actors than about maximizing own payoffs. Enhancing the saliency (cf. Handgraaf, van Dijk, Vermunt, \& Wilke, 2003) of the increase of monetary capital (intrapersonal comparison) might make the motive of maximizing personal payoffs more prominent and may convince individualists to increase cooperation against TFT-1. Based on our second study we conclude that the MinDiff motive is guiding choice procedures among individualists. As long as unequal distributions of payoffs are enduring, individualists are willing to forego personal gains. We find that individualists increase their level of cooperation when the unequal distribution of payoffs dissipates.

Based on study 1, we could explain the lower levels of cooperation among individualists against TFT-1 simply as a main effect of social value orientation. Previous research has indicated that prosocials display greater willingness to cooperate (e.g. De Cremer \& Van Lange, 2001; Kuhlman \& Marshello, 1975; McClintock \& Liebrand, 1988). Despite the fact that we predicted higher levels of cooperation among individualists against TFT-1, social value theory could also predict that prosocials always show a greater tendency to cooperate. In our second study we can partly rule out this explanation. The lower levels of cooperation against TFT-1 among individualists is not simply due to a generalized noncooperative mindset, because we find a greater willingness to restore cooperation against TFT among individualists. The noncooperative behavior of individualists against TFT- 1 is therefore not likely to be due to a noncooperative mindset. Future research could try to investigate potential explanations for this stronger inequality aversion among individualists. The ability to compare oneself with others (e.g. Festinger, 1954) is phylogenetically very old and is recognizable in many species (Gilbert, Price, \& Allan, 1995). However, as noted by Gibbons and Buunk (1998), the extent to which people compare themselves with others varies from one individual to the next (as assessed by the social comparison orientation (SCO) scale). It may be possible that individualists attain higher scores on the SCO scale than prosocials do.

Our findings may also have implications for the SVO measure. A widely used technique to measure one's social value orientation is the Triple Dominance Measure (TDM) of Social Values (see e.g. Van Lange, Otten, De Bruin, \& Joireman, 1997). Despite the excellent psychometric qualities of the TDM, our findings point at a possible confound in this 
questionnaire. The option for maximizing own gains in the TDM never coincides with equal outcomes for both parties: Maximizing own payoffs means also that the other is receiving less, whereas the option that maximizes joint outcomes always coincides with equal outcomes for both players. Hence, the TDM confounds the tendency to enhance joint outcomes with the motivation to enhance equality in outcomes. The TDM fails to distinguish between prosocials' motives to achieve equal outcomes or to maximize joint outcome. Previous research has suggested that enhancing joint outcomes and equality in outcomes constitute two relatively independent dimensions (De Cremer \& Van Lange, 2001), so one could question whether it is justified that both dimensions are captured within a single option in the TDM. Recent evidence indicates that prosocials prefer equal outcomes to maximizing joint outcomes (Eek \& Gärling, in press) and our research adds another question mark to the assessment of social value orientation with the TDM: Our two experiments are indicative for a MinDiff component among individualists and argue in favor of an 'new' option in the TDM (e.g. you: 480 and other: 540) which maximizes joint outcomes while being inconsistent with the motive to maximize own (you: 540 and other: 280) or minimize the differences between the actors (you: 480 and other: 480). It remains possible however that prosocials and individualists differ from one another in situations where the unequal distribution of payoffs is advantageous for oneself (cf. Loewenstein, Thompson, \& Bazerman, 1989). We cannot rule out the possibility that prosocials dislike receiving more than another individual (which is also a violation of equal distribution of payoffs) whereas individualists do not care about a difference in the advantage of the self. When individualists are typified as maximizers of one's own outcomes with little or no regard for outcomes for others, this characterization may only apply in situations where the inequality in outcomes is advantageous for oneself.

Both the integrative model of social value orientation (Van Lange, 1999) and a widely used measurement of social value orientation, assume that the concern for equality is virtually absent in individualists. This is puzzling since the concern about equality in outcomes is found in monkeys and apes (Brosnan \& de Waal, 2003; Brosnan, Schiff, \& de Waal, 2005) and thus seems to have evolutionary precursors. The tendency to enhance equality in outcomes is not something uniquely human. Our experimental studies show that both prosocials and individualists forego personal or dyadic gains if another individual receives more than oneself, which is consistent with behavior of non-human primates (Brosnan \& de Waal, 2003; Brosnan, Schiff, \& de Waal, 2005). Foregoing personal gains might seem maladaptive from an evolutionary point of view, but detecting and refusing to cooperate with exploiters can be an important adaptation in order to prevent a higher fitness coefficient for these free-riders (Cosmides \& Tooby, 1992). Therefore, refusing to cooperate and foregoing personal gains when interacting with exploitative strategies 
should be favored by natural selection at a short term cost for the player. Equality considerations are probably complex adaptations distributed in a species-typical fashion. Our two experiments indicate that prosocials are not unique in their egalitarianism: Individualists are as willing to give up personal gains if outcomes are distributed unequally. 


\section{References}

Axelrod, R. (1984). The evolution of cooperation. New York: Basic Books.

Bazerman, M., Loewenstein, G., \& White, S. (1992). Reversals of preference in allocation decisions: Judging an alternative versus choosing among alternatives. Administrative Science Quarterly, 37, 220-240.

Bazerman, M. H., White, S. B., \& Loewenstein, G. F. (1995). Perceptions of fairness in interpersonal and individual choice situations. Current Directions in Psychological Science, 4, 3943.

Brosnan, S. F., \& de Waal, F.B.M. (2003). Monkeys reject unequal pay. Nature, 425, 297-299.

Brosnan, S. F., Schiff, H. C., \& de Waal, F. B. M. (2005). Tolerance for inequity may increase with social closeness in chimpanzees. Proceedings of the Royal Society of London, Series B, 272, 253-258.

Camerer, C. F., \& Thaler, R. H. (1995). Anomalies: Ultimatums, dictators and manners. The Journal of Economic Perspectives, 9, 209-219.

Cosmides, L., \& Tooby, J. (1992). Cognitive adaptations for social exchange. In J. H. Barkow, L. Cosmides, \& J. Tooby (Eds.), The adapted mind: evolutionary psychology and the generation of culture (pp. 163-228). New York: Oxford University Press.

Dawes, R. M. (1980). Social dilemmas. Annual Review of Psychology, 31, 169-193.

Dawes, R. M. \& Thaler, R. H. (1988). Anomalies: Cooperation. Journal of Economic Perspectives, 2, 187-197.

De Cremer, D., \& Van Lange, P. A. M. (2001). Why prosocials exhibit greater cooperation than proselfs: The roles of social responsibility and reciprocity. European Journal of Personality, 15, 518.

Eek, D., \& Gärling, T. (in press). Prosocials prefer equal outcomes to maximizing joint outcome. British Journal of Social Psychology.

Festinger, L. (1954). A theory of social comparison processes. Human Relations, 7, 117-140.

Gibbons, F. X., \& Buunk, B. P. (1999). Individual differences in social comparison: Development and validation of a measure of social comparison orientation. Journal of Personality and Social Psychology, 76, 129 - 142.

Gilbert, P., Price, J., \& Allan, S. (1995). Social comparison, social attractiveness and evolution: How might they be related? New Ideas in Psychology, 13, 149-165.

Guth, W., Schmittberger, R., \& Schwarze, B. (1982). An experimental analysis of ultimatum bargaining. Journal of Economic Behavior and Organization, 3, 367-388.

Handgraaf, M. J. J., van Dijk, E., Vermunt, R. \& Wilke, H. A. M. (2003). The salience of a recipient's alternatives: Inter- and intrapersonal comparison in ultimatum games. Organizational Behavior and Human Decision Processes, 90, 165-177. 
Loewenstein, G., Thompson, L., \& Bazerman, M. (1989). Social utility and decision making in interpersonal contexts. Journal of Personality \& Social Psychology, 57, 426-441.

Liebrand, W.B.G., Jansen, R.W.T.L., Rijken, V.M., and Suhre, C.J.M. (1986). Might over morality: Social values and the perception of other players in experimental games. Journal of Experimental Social Psychology, 22, 203-215.

Kelley, H. H., \& Stahelski, A. J. (1970). Social interaction basis of cooperators' and competitors' beliefs about others. Journal of Personality and Social Psychology, 16, 66-91.

Komorita, S. S., Hilty, J. H., \& Parks, C. D. (1991). Reciprocity and cooperation in social dilemmas. Journal of Conflict Resolution, 35, 494-518.

Kuhlman, D., \& Marshello, A. (1975). Individual differences in game motivation as moderators of preprogrammed strategy effects in prisoner's dilemma. Journal of Personality and Social Psychology, 32, 922-931.

McClintock, C. G., \& Liebrand, W. B. G. (1988). Role of interdepence structure, individual value orientation, and another's strategy in social decision making: A transformational analysis. Journal of Personality and Social Psychology, 55, 396-409.

McClintock, C. G. (1972). Social motivation - a set of propositions. Behavioral Science, 17, 438-454.

Messick, D. M. (1993). Equality as a decision heuristic. In B. A. Mellers \& J. Baron (Eds.), Psychological perspectives on justice: Theory and applications. Cambridge series on judgment and decision making (pp. 11-31). New York: Cambridge University Press.

Messick, D. M., \& McClintock, C. G. (1968). Motivational basis of choice in experimental games. Journal of Experimental Social Psychology, 4, 1-25.

Oskamp, S. (1971). Effects of programmed strategies on cooperation in the Prisoner's Dilemma and other mixed-motive games. Journal of Conflict Resolution, 15, 225-259.

Parks, C. D., \& Rumble, A. C. (2001). Elements of reciprocity and social value orientation. Personality and Social Psychology Bulletin, 27, 1301-1309.

Parks, C. D., Rumble, A. C., \& Posey, D. C. (2002). The effects of envy on reciprocation in a social dilemma. Personality and Social Psychology Bulletin, 28, 509-520.

Samuelson, C. D., \& Allison, S. T. (1994). Cognitive factors affecting the use of social decision heuristics in resource-sharing tasks. Organizational Behavior and Human Decision Processes, 58, 127.

Sheldon, K. M. (1999). Learning the lessons of tit-for-tat: Even competitors can get the message. Journal of Personality and Social Psychology, 77, 1245-1253.

Stouten, J., De Cremer, D., \& van Dijk, E. (in press). All is well that ends well, at least for proselfs: Emotional reactions to equality violation as a function of social value orientation. European Journal of Social Psychology. 
van Dijk, E., De Cremer, D., \& Handgraaf, M. J. J. (2004). Social value orientations and the strategic use of fairness in ultimatum bargaining. Journal of Experimental Social Psychology, 40, 697-707.

Van Lange, P. A. M. (1999). The pursuit of joint outcomes and equality in outcomes: An integrative model of social value orientation. Journal of Personality and Social Psychology, 77, 337-349.

Van Lange, P. A. M., \& Kuhlman, D. M. (1994). Social value orientations and impressions of partner's honesty and intelligence: A test of the Might Versus Morality effect. Journal of Personality and Social Psychology, 67, 126-141.

Van Lange, P. A. M., Otten, W., de Bruin, E. M. N., \& Joireman, J. A. (1997). Development of prosocial, individualistic, and competitive orientations: Theory and preliminary evidence. Journal of Personality and Social Psychology, 73, 733-746.

Van Lange, P. A. M., Ouwerkerk, J. W., \& Tazelaar, M. J. A. (2002). How to overcome the detrimental effects of noise in social interaction: The benefits of generosity. Journal of Personality and Social Psychology, 82, 768-780.

Van Lange, P. A. M., \& Visser, K. (1999). Locomotion in social dilemmas: How people adapt to cooperative, tit-for-tat, and noncooperative partners. Journal of Personality and Social Psychology, 77, 762-773.

Wilson, W. (1971). Reciprocation and other techniques for inducing cooperation in the Prisoner's Dilemma game. Journal of Conflict Resolution, 15, 167-195. 
Author Note

Bram Van den Bergh, Department of Applied Economics, University of Leuven (Belgium); Siegfried Dewitte, Department of Applied Economics, University of Leuven (Belgium); David De Cremer, Department of Economic and Social Psychology, Tilburg University (Netherlands).

The first author is supported by a Junior Researcher (Aspirant) Grant from the Fund for Scientific Research - Flanders, Belgium (FWO). The second author is supported by grant G.0391.03 from the Fund for Scientific Research - Flanders, Belgium (FWO) and a research grant of the Katholieke Universiteit Leuven (OT 03/07). The third author is supported by the Netherlands Organization for Scientific Research (NOW, Grant No. 016). Financial support by Censydiam-Synovate is gratefully acknowledged.

Correspondence concerning this article should be addressed to Bram Van den Bergh, University of Leuven, Department of Applied Economics, Naamsestraat 69, B-3000 Leuven, Belgium. E-mail: bram.vandenbergh@econ.kuleuven.be 


\section{Figure Captions}

Figure 1. The mean number of coins given away (Y-axis) by prosocials and individualists on each round (X-axis) in the TFT and TFT-1 condition.

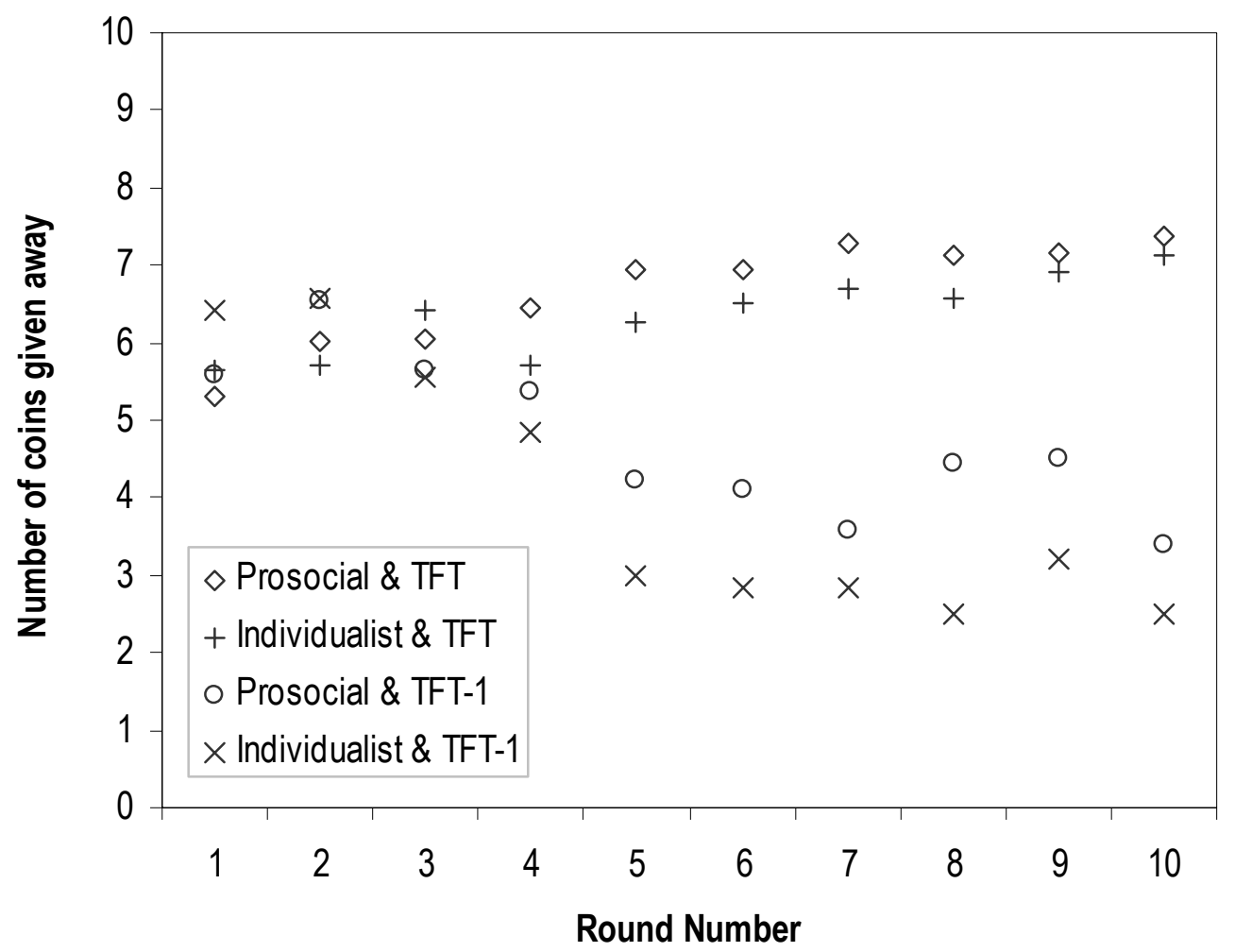


Figure 2. The mean number of coins given away (Y-axis) by prosocials and individualists on each round (X-axis). The first 20 rounds the opponent pursued a TFT- 1 strategy, the last 20 rounds the opponent pursued a TFT strategy.

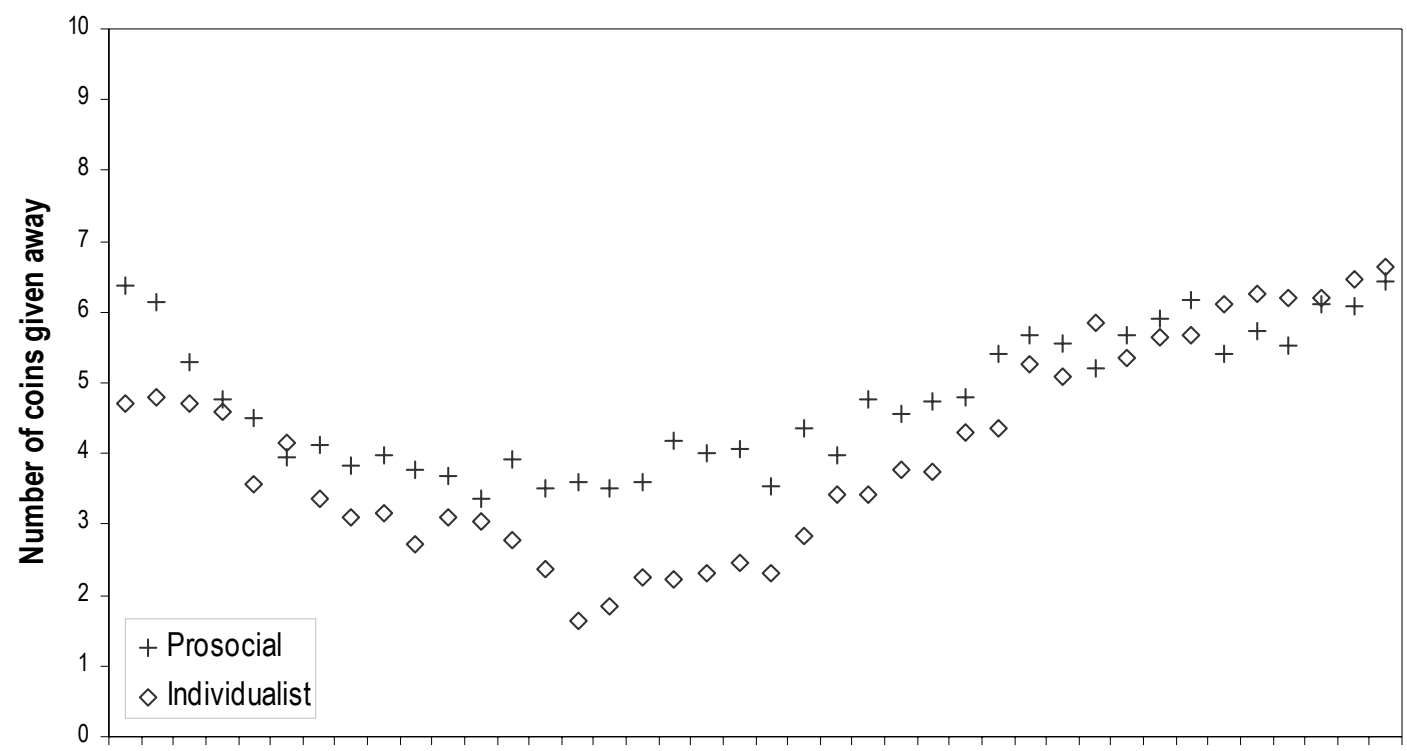

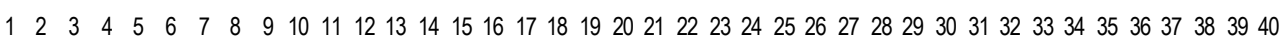

Round Number 